\title{
Freezing of gait and response conflict in Parkinson's disease: computational directions
}

\begin{abstract}
Ahmed A. Moustafa*
Marcs Institute for Brain and Behaviour and School of Social Sciences and Psychology, University of Western Sydney, Sydney, NSW, Australia

${ }^{*}$ Correspondence: a.moustafa@uws.edu.au
\end{abstract}

Edited and reviewed by:

Hava T. Siegelmann, Rutgers University, USA

Keywords: Parkinson's disease, freezing of gait, response conflict, computational modeling

\section{A commentary on}

Using virtual reality to explore the role of conflict resolution and environmental salience in Freezing of Gait in Parkinson's disease

by Matar, E., Shine, J. M., Naismith, S. L., and Lewis, S. J. (2013). Parkinsonism Relat. Disord. 19, 937-942. doi: 10.1016/j.parkreldis.2013.06.002

In a recent study, Matar et al. (2013) found that Parkinson's disease (PD) patients with freezing of gait significantly displayed reduced locomotive responses when passing through narrow rather than wide doors and while facing the opening of a sliding door. Freezing of gait refers to a cessation of movement despite the intention to walk forward, such that patients often feel like their feet have been "glued to the ground" (Schaafsma et al., 2003; Rahman et al., 2008). This pattern of results was not found with PD patients without freezing of gait or healthy controls. The Matar et al. study can potentially point to which environmental situations can lead to freezing of gait in $\mathrm{PD}$ patients.

Most interestingly, these results were reported by using a "virtual" setting in which subjects navigate a realistic threedimensional environment using foot pedals (see Figure 1, also see Naismith and Lewis, 2010). The virtual reality paradigm used in the Matar et al. (2013) study is used for testing perceptual and cognitive factors underlying successful locomotion in humans. In this paradigm, forward progression in the virtual environment (left side of Figure 1) only occurs by alternating left-right sequences of footsteps (right side of Figure 1). The time taken between the footsteps (left-right or right-left) corresponds to faster or slower progression in the virtual environment, thus mimicking natural walking. In the Matar et al. study, the virtual environment contains corridors with doorways (as shown in Figure 1) and/or salient environmental stimuli that prompt locomotive responses. The Matar et al. data confirms and also extends prior results that have used real doorways (Almeida and Lebold, 2010; Cowie et al., 2010; Knobl et al., 2012).

The virtual reality paradigm also allows the testing of more abstract cognitive cues on freezing of gait. Interestingly, the same study by Matar et al. also show that subjects with freezing of gait (but not other groups) slow down when instructed to "walk" when presented with word "RED" in red-font rather than "GREEN" in green font (Matar et al., 2013). Although non-significant, healthy controls took longer time to respond to the "RED" than "GREEN" cue. The authors suggested that the red cue is implicitly associated with stopping action (e.g., red-light traffic signals), and thus instructing subjects to walk when presenting with the red cue can lead to response conflict (e.g., conflict resulting from deciding whether to walk quickly, slowly, or stop). The authors further argue that $\mathrm{PD}$ patients with freezing of gait have a response conflict processing deficit, which leads to slow locomotion during the presentation of the red cue.

It is argued that an impaired response conflict mechanism can explain the freezing of gait phenomenon (Matar et al., 2013; Shine et al., 2013). For example, Matar et al. argue that the same response conflict mechanism can also explain the differential effects of doorway size on locomotive speed: While passing through

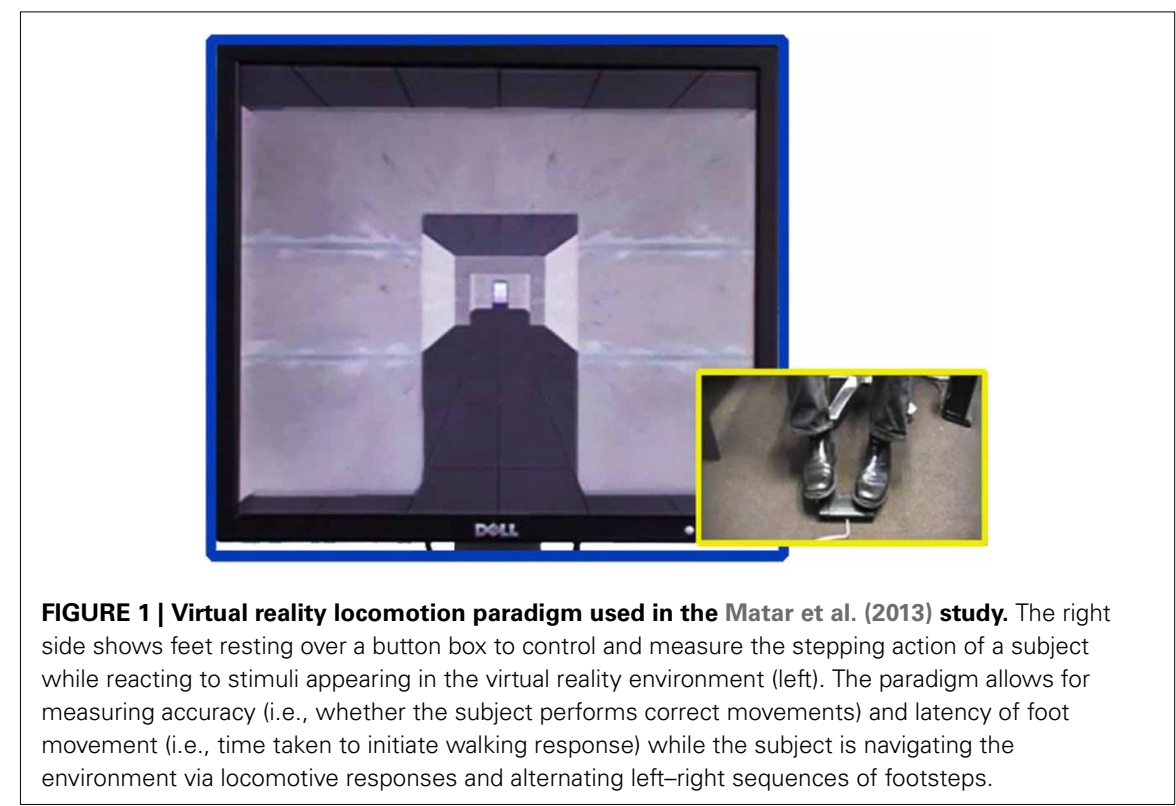


the narrow door, subjects might hit the wall, and will think about various other motor responses, which might induce response conflict. The same mechanism also explains reduced locomotive speed while facing a sliding door. Interestingly, the same response conflict mechanism can also explain prior studies showing that avoiding obstacles (Snijders et al., 2010) or making a turn (Spildooren et al., 2010) might lead to freezing of gait in PD patients.

What is the neural mechanism underlying freezing of gait and response conflict? Shine et al. (2013) found that PD patients with freezing of gait show aberrant neural activation in the pre-supplementary motor area and subthalamic nucleus (STN) in situations that involve choosing either to walk or stop. Along the same lines, Frank et al. (2007) found that PD patients tested on STN DBS respond faster in conflicting situations than the same patients tested off their STN DBS, suggesting that STN plays a role in the time taken to generate a motor response. Most prior studies of the role of the STN in response conflict employed hand movements (Frank et al., 2007; Isoda and Hikosaka, 2008); however, it is not known if the STN plays a similar role in locomotion (i.e., whether the STN controls timing of locomotive responses). For a recent review for the role of STN in highconflict decision making, see Weintraub and Zaghloul (2013).

Future computational network modeling research is needed to tie together behavioral and neural data regarding the occurrence of freezing of gait in Parkinson's disease. The importance of these models is to explain seemingly different phenomena, such as the relationship between freezing of gait and response conflict, as well as the role of STN in these processes. Such models can provide a mechanistic account for the role of cortex-basal ganglia interactions, and can also simulate the dissociable effects the dopamine medications and deep brain stimulation on freezing of gait. For example, computational models by Frank and colleagues can potentially explain the occurrence of freezing of gait in Parkinson's disease patients (Frank, 2006; Frank et al., 2007). In these models, the STN acts as a global inhibition mechanism, such as to inhibit motor processes during high-conflict situations. The model suggests freezing of gait occurs in high-conflict situation due the over activation of the STN, which leads to inhibition of motor output and thus freezing of gait.

Future experimental research should also test the dissociable effects of different dopaminergic therapies (e.g., levodopa, dopamine agonists, MAO inhibitors) on freezing of gait in relation to environmental contexts in which it commonly occurs. The success of the virtual reality paradigm to reveal perceptual and cognitive factors underlying freezing behavior will open venues for studying more complex paradigms in which locomotive responses may be disrupted, such as while driving or crossing the street.

\section{ACKNOWLEDGMENTS}

This Research is partially supported by a 2013 internal UWS Research Grant Scheme award P00021210 to Ahmed A. Moustafa.

\section{REFERENCES}

Almeida, Q. J., and Lebold, C. A. (2010). Freezing of gait in Parkinson's disease: a perceptual cause for a motor impairment? J. Neurol. Neurosurg. Psychiatry 81, 513-518. doi: 10.1136/jnnp.2008.160580

Cowie, D., Limousin, P., Peters, A., and Day, B. L. (2010). Insights into the neural control of locomotion from walking through doorways in Parkinson's disease. Neuropsychologia 48, 2750-2757. doi: 10.1016/j.neuropsychologia.2010.05.022

Frank, M. J. (2006). Hold your horses: a dynamic computational role for the subthalamic nucleus in decision making. Neural Netw. 19, 1120-1136. doi: 10.1016/j.neunet.2006.03.006

Frank, M. J., Samanta, J., Moustafa, A. A., and Sherman, S. J. (2007). Hold your horses: impulsivity, deep brain stimulation, and medication in parkinsonism. Science 318, 1309-1312. doi: 10.1126/science. 1146157

Isoda, M., and Hikosaka, O. (2008). Role for subthalamic nucleus neurons in switching from automatic to controlled eye movement. J. Neurosci. 28, 7209-7218. doi: 10.1523/JNEUROSCI.048708.2008

Knobl, P., Kielstra, L., and Almeida, Q. (2012). The relationship between motor planning and freezing of gait in Parkinson's disease. J. Neurol. Neurosurg. Psychiatry 83, 98-101. doi: 10.1136/jnnp-2011300869

Matar, E., Shine, J. M., Naismith, S. L., and Lewis, S. J. (2013). Using virtual reality to explore the role of conflict resolution and environmental salience in Freezing of Gait in Parkinson's disease. Parkinsonism Relat. Disord. 19, 937-942. doi: 10.1016/j.parkreldis.2013.06.002

Naismith, S. L., and Lewis, S. J. (2010). A novel paradigm for modeling freezing of gait in Parkinson's disease. J. Clin. Neurosci. 17, 984-987. doi: 10.1016/j.jocn.2009.12.006

Rahman, S., Griffin, H. J., Quinn, N. P., and Jahanshahi, M. (2008). The factors that induce or overcome freezing of gait in Parkinson's disease. Behav. Neurol. 19, 127-136. doi: 10.1155/2008/456298

Schaafsma, J. D., Balash, Y., Gurevich, T., Bartels, A. L., Hausdorff, J. M., and Giladi, N. (2003). Characterization of freezing of gait subtypes and the response of each to levodopa in Parkinson's disease. Eur. J. Neurol. 10, 391-398. doi: 10.1046/j.1468-1331.2003.00611.x

Shine, J. M., Matar, E., and Lewis, S. J. (2013). Differential neural activation patterns in patients with Parkinson's disease and freezing of gait in response to concurrent cognitive and motor load. PLoS ONE 8:e52602. doi: 10.1371/journal.pone. 0052602

Snijders, A. H., Weerdesteyn, V., Hagen, Y. J., Duysens, J., Giladi, N., and Bloem, B. R. (2010). Obstacle avoidance to elicit freezing of gait during treadmill walking. Mov. Disord. 25, 57-63. doi: 10.1002/mds. 22894

Spildooren, J., Vercruysse, S., Desloovere, K., Vandenberghe, W., Kerckhofs, E., and Nieuwboer, A. (2010). Freezing of gait in Parkinson's disease: the impact of dual-tasking and turning. Mov. Disord. 25, 2563-2570. doi: 10.1002/ mds. 23327

Weintraub, D. B., and Zaghloul, K. A. (2013). The role of the subthalamic nucleus in cognition. Rev. Neurosci. 24, 125-138. doi: 10.1515/revneuro2012-0075

Received: 22 October 2013; accepted: 10 January 2014; published online: 28 January 2014.

Citation: Moustafa AA (2014) Freezing of gait and response conflict in Parkinson's disease: computational directions. Front. Comput. Neurosci. 8:7. doi: 10.3389/ fncom.2014.00007

This article was submitted to the journal Frontiers in Computational Neuroscience.

Copyright (c) 2014 Moustafa. This is an open-access article distributed under the terms of the Creative Commons Attribution License (CC BY). The use, distribution or reproduction in other forums is permitted, provided the original author(s) or licensor are credited and that the original publication in this journal is cited, in accordance with accepted academic practice. No use, distribution or reproduction is permitted which does not comply with these terms. 